\title{
Effectiveness of high speed instrument and air abrasion on different dental substrates
}

Lívia Azeredo Alves Antunes ${ }^{(a)}$ Rafael Lima Pedro(a)

Áurea Simone Barrôso Vieira ${ }^{(b)}$ Lucianne Cople Maia(c)

(a) Master of Science Students; (b) Master of Science; ${ }^{(c)}$ Associate Professor - Department of Pediatric Dentistry and Orthodontics, School of Dentistry, Federal University of Rio de Janeiro, RJ, Brazil.
Corresponding author:

Lucianne Cople Maia

Rua Gastão Gonçalves, 47

apło 501 - Santa Rosa

Niterói - Rio de Janeiro - Brazil

CEP: 24240-030

E-mail: rorefa@terra.com.br

Received for publication on Oct 06, 2006

Accepted for publication on Aug 02, 2007

\begin{abstract}
The aim of this study was to compare the effectiveness of high speed (HS) and air abrasion (AA) instruments on groups of teeth (deciduous, permanent, bovine), in terms of preparation time, topography and presence of smear layer. Each group consisted of 5 teeth that had their buccal/lingual surfaces prepared by using either HS or AA. All procedures were standardized and timed. The teeth were then sectioned and prepared for evaluation of both the topography and the presence of smear layer by scanning electron microscopy. As regards preparation time, HS yielded preparations 1.5 times quicker than AA did on the three types of dental substrates (Wilcoxon test, $\mathrm{p}<0.05$ ). In both techniques (KruskalWallis Test, $\mathrm{p}<0.05$ ) the preparation time was influenced by the dental substrate, particularly in deciduous teeth (Mann-Whitney test with Bonferoni's correction, $\mathrm{p}<0.017$ ), which required a longer preparation time. In the descriptive analysis of the topography, no difference was found between the substrates. Nonetheless, the different instruments used determined distinctive topographies. Both techniques produced a smear layer $\left(\chi^{2}\right.$ McNemar, $\left.p>0.05\right)$ in all substrates, but with different formations. In conclusion, the HS instrument was found to be more rapid than the AA. No difference was found between the three dental substrates as regards both the topography and the presence of smear layer. The differences found in the present study were only in relation to the effects of each instrument used.
\end{abstract}

Descriptors: Tooth preparation; Air abrasion, dental; Tooth, deciduous; Microscopy, electron, scanning; In vitro. 


\section{Introduction}

The development of caries removal techniques has become increasingly conservative and biological. This has been made possible by a better understanding of the etiology and prevention of dental caries. In addition, an advanced concept of cavity preparation has emerged as a result of the introduction of acid-etching techniques, adhesive restorative materials, and the development of new cavity preparations systems, such as air abrasion systems. ${ }^{1}$

According to Eick et al. ${ }^{2}$ (1972) and Nakabayashi et al. ${ }^{3}$ (1982), the structural integrity and surface characteristics of the tooth after caries excavation may be relevant to the adhesiveness of the restorative material to be used. Therefore, it should be borne in mind that even an ideal cutting instrument must fulfill the requirements established for both patient and practitioner, despite the development of alternative cavity preparation techniques. ${ }^{4}$ Moreover, speed and effectiveness of carious tissue removal, ${ }^{5}$ resulting in satisfactory morphology with minimum formation of smear layer, so that the adhesive restorative materials can be properly applied, are important features ${ }^{6}$ for preparing a dental cavity without interfering with tooth restoration. Furthermore, the increasing use of different dental substrates (bovine, deciduous, and permanent teeth) in research emphasizes the importance of cavity preparation techniques when such teeth are involved.

By taking factors such as these into account, the aim of the present study was to compare in vitro the effects of high speed and air abrasion instruments on deciduous, permanent and bovine teeth, in terms of preparation time, topography, and presence of smear layer.

\section{Material and Methods}

This study was conducted after being approved by the local Ethics Committee. Altogether, 15 teeth (5 deciduous teeth, group D; 5 permanent teeth, group $\mathrm{P}$; and 5 bovine teeth, group B) were selected using a light microscope (40 X), and none of them were found to have structural alterations. All the teeth were stored in physiological solution (changed every week) until the beginning of the experiment.

The teeth were sectioned mesiodistally by us- ing a double-faced diamond disc (KG Sorensen, São Paulo, SP, Brazil) obtaining two surfaces (buccal and lingual) that were fixed on acrylic bases.

Class V cavity preparations $(\mathrm{n}=30)$ were randomly performed on the buccal and lingual surfaces by one operator only. The instruments used were a diamond tip (1061, KG Sorensen, São Paulo, SP, Brazil) mounted on a high speed device (605 extra torque, Kavo, Joinville, SC, Brazil) $(\mathrm{n}=15)$ and an air abrasion system (RONDOflex 2013, Kavo, Biberach, Riss, Germany) with a $120^{\circ}$ tip, $0.64 \mathrm{~mm}$ in diameter. Air abrasion was carried out with $50 \mu \mathrm{m}$ aluminum oxide grains at a pressure of 80 psi and distance of $1 \mathrm{~mm}$ from the tooth surface.

As regards the cavity preparations, the dimensions were standardized to $2.0 \times 2.0 \times 2.5 \mathrm{~mm}$ by using a millimetric probe (Hu-Friedy, Zweigniederlassung Deutschland, Leimen, Germany) for measuring the depth, and digital caliper (Mitutoyo, Tokyo, Japan) for measuring width and length.

The diamond tips were changed after every 5 cavity preparations and the air abrasion instrument was cleaned after every 2.

The time spent on each cavity preparation was recorded with a chronometer (Technos, Manaus, AM, Brazil) and the data were then tabulated. The Wilcoxon $(\mathrm{p}<0.05)$, Kruskal-Wallis $(\mathrm{p}<0.05)$, and Mann-Whitney tests, as well as Bonferroni's correction $(p<0.017)$ for non-paired correlation, were used for statistical analysis of instruments and substrates.

Topographic evaluation of the cavity preparations was based on photomicrographs and quantitative and qualitative parameters were taken into account.

With regard to the qualitative topographic analysis, the cavities were cervicoincisally sectioned into 60 fragments. Next, these samples were prepared for examination by scanning electron microscopy (SEM) (JEOL - Model JSM - 5310, Tokyo, Japan). At a $35 \mathrm{X}$ magnification, the topography of the cavities could be externally observed. At a 2,000 X magnification, the dentine of the different substrates could be internally observed.

The quantitative analysis was performed by two investigators, based on the photomicrographs 
$(2,000 \mathrm{X})$ of the smear layer $(\mathrm{Kp}=0.98)$, and scores were adopted ${ }^{7}$ according to McNemar's chi-square test $(\mathrm{p}<0.05)$.

\section{Results}

With respect to preparation time (Table 1 ), it was found that the high speed instruments yielded cavity preparations, on average, 1.5 times more rap-

Table 1 - Cavity preparation time (in seconds) according to instrument used in the three types of dental substrates.

\begin{tabular}{l|l|c|l|c}
\hline \multirow{2}{*}{ Group } & \multicolumn{4}{c}{ Time (seconds) } \\
\cline { 2 - 5 } & \multicolumn{2}{|c}{ High speed } & \multicolumn{2}{c}{ Air abrasion } \\
\cline { 2 - 5 } & Mean & SD & Mean & SD \\
\hline Deciduous* & $43.20^{\mathrm{aA}}$ & \pm 2.58 & $68.40^{\mathrm{bA}}$ & \pm 17.22 \\
\hline Permanent & $31.40^{\mathrm{a}^{\prime} \mathrm{B}}$ & \pm 2.70 & $45.00^{\mathrm{b}^{\prime} \mathrm{B}^{\prime}}$ & \pm 7.58 \\
\hline Bovine & $35.20^{\mathrm{a}^{\prime \prime} \mathrm{C}}$ & \pm 5.45 & $47.60^{\mathrm{b}^{\prime \prime} \mathrm{C}^{\prime}}$ & \pm 6.10 \\
\hline
\end{tabular}

Different letters indicate statistical significance: row $=$ normal letter $(\mathrm{Wil}$ coxon test); column = capital letter (Kruskal-Wallis test). ${ }^{*}$ Mann-Whitney test with Bonferroni's correction $p<0.01$.
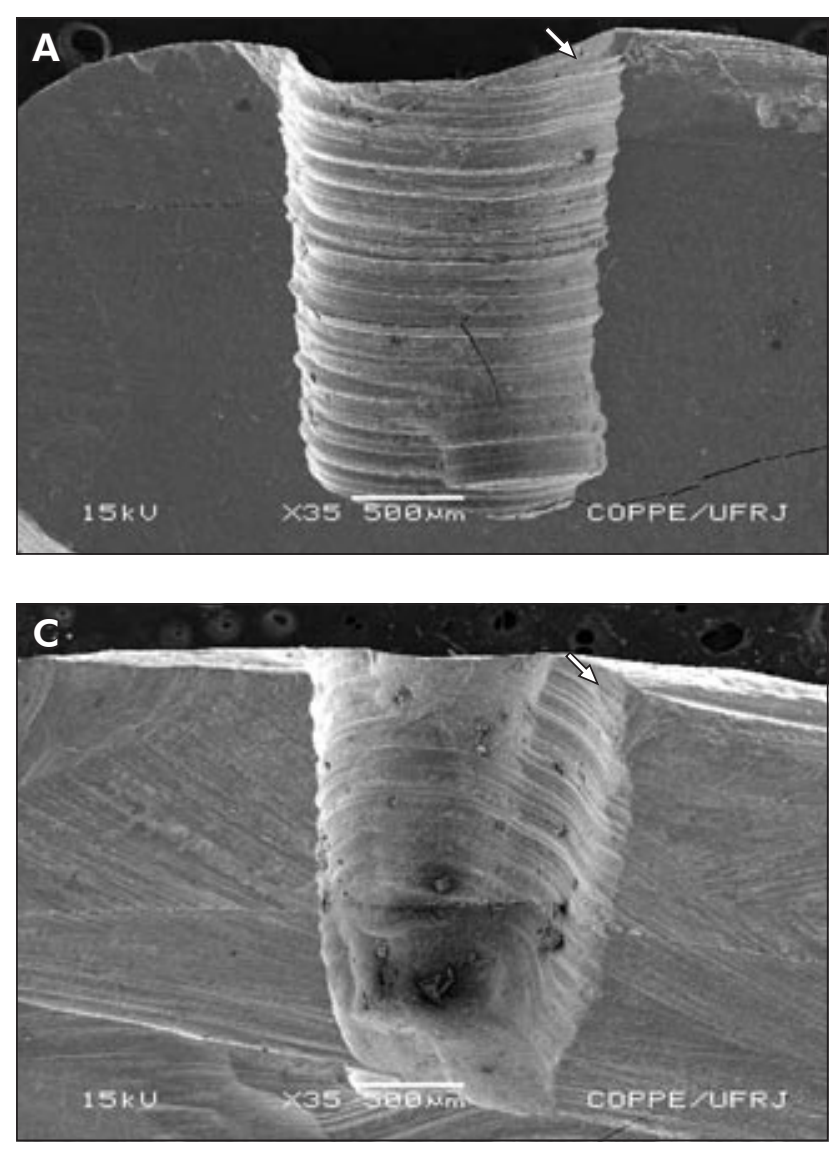

idly than the air abrasion instruments with regard to the three types of dental substrates. The dental substrates influenced the preparation time irrespective of the instrument used, and cavities involving permanent teeth were prepared more rapidly than those in bovine and deciduous substrates. Delay in preparing deciduous teeth was found to be statistically significant.

With respect to topography, descriptive analysis of Groups D, P, and B showed that the high speed instrument yielded more uniform, U-shaped cavities with defined cavosurface and inner angles, as well as grooves on both enamel and dentine (Figure 1), whereas the air abrasion system yielded more irregular, W- or V-shaped cavities with cavosurface and internal contours forming a margin around the cavity preparation. Moreover, enamel and dentine had an irregular aspect with the presence of aluminum oxide (Figure 2).

With respect to the smear layer, both instruments yielded its formation in all teeth $\left(\chi^{2}\right.$ McNemar,

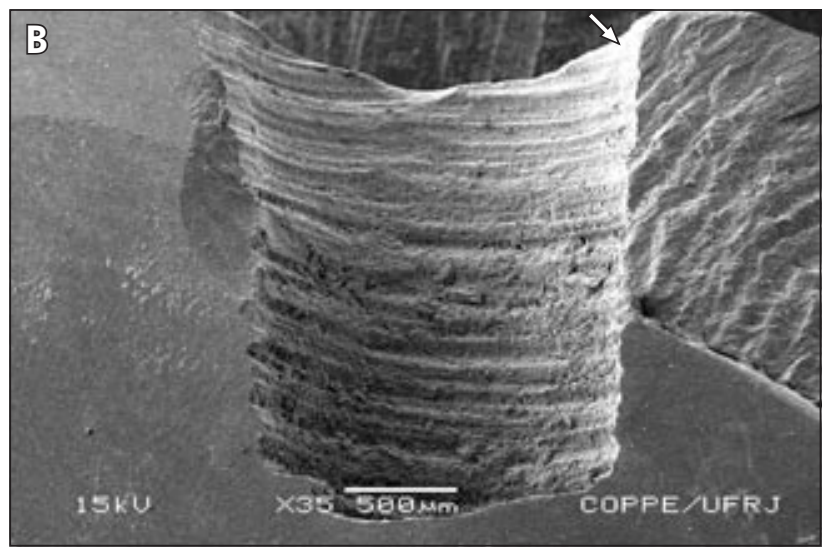

Figure 1 - Substrate topographies resulting from the use of the high speed instrument: (A) deciduous, (B) permanent, and $(\mathbf{C})$ bovine. Note the design of the cavosurface margin (arrows) (Original Magnification 35 X). 

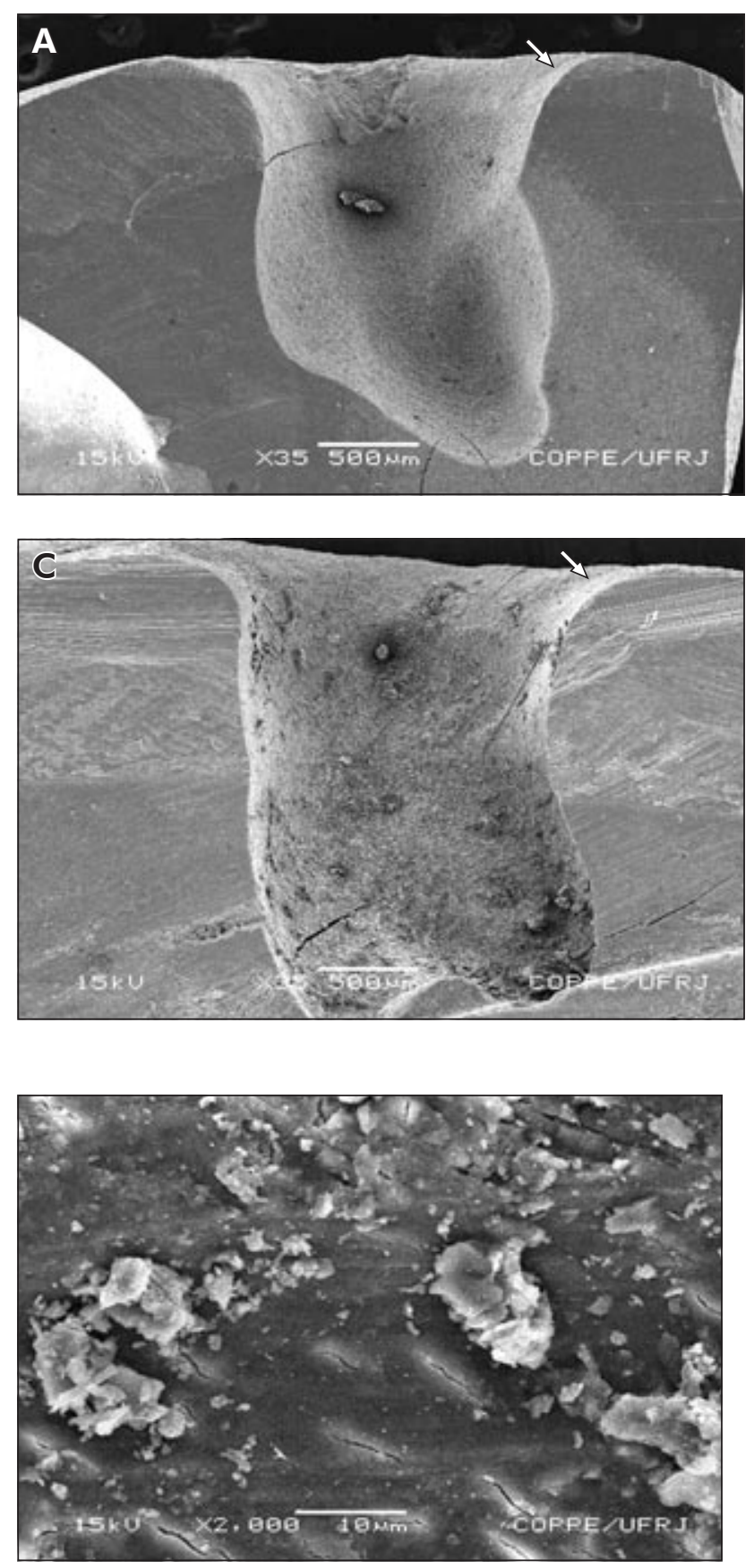

Figure 3 - Aspect of the smear layer produced by the high speed instrument (Original magnification 2,000 X).

$\mathrm{p}>0.05)$. However, descriptive analysis revealed different smear layer formations depending on the instrument used. The smear layer produced by the mechanical rotary instrument (HS) was shown to be an amorphous layer on the dentine surface. This compact and non-organized layer was apparently

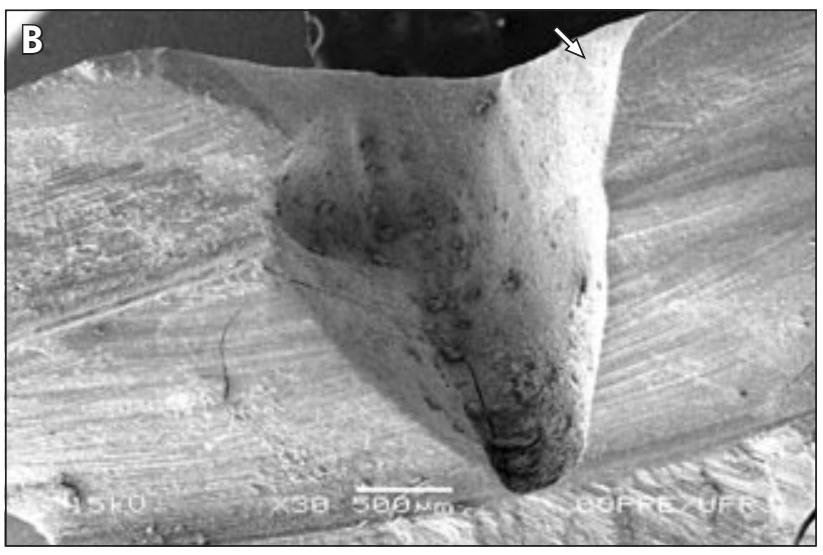

Figure 2 - Substrate topographies resulting from the use of the air abrasion instrument: (A) deciduous, (B) permanent, and $(\mathbf{C})$ bovine. Note the design of the cavosurface margin (arrows) (Original Magnification 35 X).

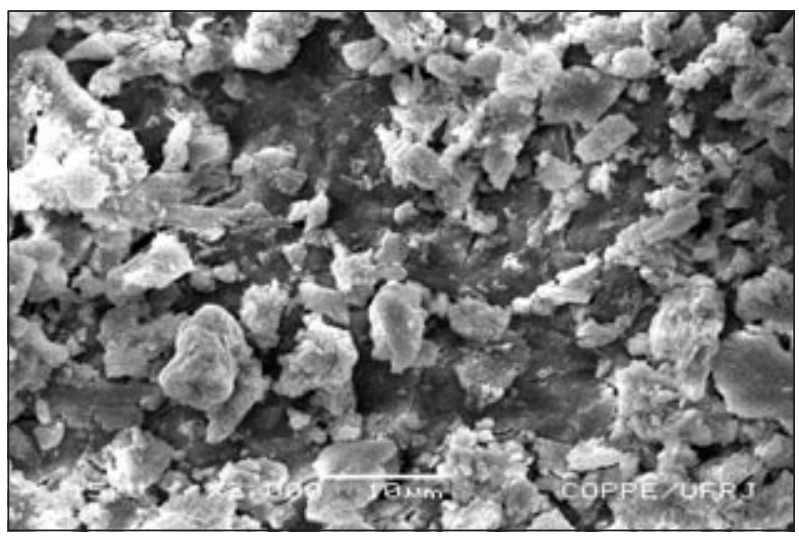

Figure 4 - Aspect of the smear layer produced by the air abrasion instrument impregnated with aluminum oxide particles (Original magnification 2,000 X).

adhered to the dentine surface (Figure 3). On the other hand, the smear layer produced by air abrasion was found to be associated with the presence of aluminum oxide, apparently less adhered to the dentine surface than the smear layer produced by the mechanical rotary instrument (Figure 4). 


\section{Discussion}

Although bovine teeth have commonly been used in research on permeability, ${ }^{8}$ adhesiveness, ${ }^{9}$ morphology and microleakage ${ }^{10}$ due to the difficulty in obtaining human permanent and deciduous teeth, ${ }^{9}$ studies comparing the effects of different preparation systems on bovine teeth are still scarce.

According to Yazici et al. ${ }^{11}$ (2002), as morphology and nature of the dentine surface are the main factors in performing adhesive techniques successfully, it is important to know the type of dentine surface obtained after using cutting instruments, so that alternative treatments, specifically designed for better adaptation and adhesion of restorative materials, can be applied, ${ }^{12}$ which justifies the present study.

Differently from the new techniques for removing carious tissue, the effectiveness of high speed rotary instruments yielding precise cutting, defined angles, and a rough surface are well established in the literature. ${ }^{13}$ Moreover, the outcomes from such instruments can be used as analysis parameters since they are widely used and accepted by dental practitioners.

Effective cutting is known to be largely related to the ease with which a given instrument removes tooth tissue, that is, minimum effort in a short time. ${ }^{13}$ However, it is very difficult to establish the time spent on preparing a cavity with either high speed or air abrasion instruments. In general, studies report that both preparation systems are fast and secure by evaluating the pre-fixation time $e^{14,15}$ or analyzing the time/weight relationship. ${ }^{16}$ In the present study, sample dimensions were standardized, and time measurements were also recorded.

Although there were small differences regarding preparation time between the three substrates, the time involved in preparing the deciduous teeth was significantly different. This can be explained by the absence of an instrument fixation apparatus. As a result, the operator had to be more careful when preparing the deciduous substrates because of their anatomy, size and smaller thickness. This situation is indeed the clinical reality that dental practitioners face when handling such teeth.

It was observed that the high speed instrument was 1.5 times quicker than the air abrasion in preparing dental cavities, thus corroborating another study. ${ }^{15}$ However, the results of air abrasion preparation time were not found to be very different, since it tended to become shorter as more preparations were performed (Table 1). Therefore, these results demonstrate that air abrasion can be considered a faster system in comparison with other alternative methods of cavity preparation, such as the ultrasonic abrasion system. For instance, in two studies performed in $2004^{17}$ and $2005^{18}$ comparing ultrasonic abrasion with a high speed system, Vieira et al. ${ }^{18}$ (2005) found that the high speed system was 7.9 and 4.9 times faster, respectively, than the ultrasonic abrasion system, thus evidencing the effectiveness of air abrasion in clinical practice.

According to Yazici et al. ${ }^{11}$ (2002), SEM observation of the dentine surface treated by different caries removal techniques helps explain the adhesive mechanisms involving composite/dentine. Since the behavior of the three types of teeth studied was found to be similar with regard to topography and presence of smear layer, this suggests that different substrates can be compared with each other.

With respect to the instruments used for cavity preparation, it could also be observed that both high speed and air abrasion systems yielded smear layer formation. However, both instruments left morphologically differentiated smear layers on the dentine surface, which was also corroborated in other studies. .,6,11

High speed instruments yielded U-shaped cavities with well defined cavosurface and inner angles, ${ }^{19}$ presence of smear layer, ${ }^{18}$ grooves on the surface left by the diamond tip, and fissures and microfractures on enamel. ${ }^{18,19}$ Watson, Cook $^{20}$ (1995) explain that this results from compression and relaxation usually caused by diamond tips and drills. Fissures and microfractures existing in the cavity walls would be the result of changes in the dental surface due to the high impact and cyclic stress caused to the tooth during the use of diamond tips at high speed. These are all disadvantages associated with microleakage and postoperative sensitivity.

On the other hand, the topographic characteristics of both enamel and dentine following air 
abrasion preparation were conservative, ${ }^{21,22}$ exhibiting irregular surfaces due to the impact of aluminum oxide particles. ${ }^{21}$ Moreover, a great number of such particles were observed on the dental surfaces, which is corroborated by Yazici et al. ${ }^{11}$ (2002) but not in another study. ${ }^{19}$

Nevertheless, the most relevant characteristic reported by the previous studies of air abrasion, ${ }^{19,21-}$ ${ }^{23}$ and also confirmed by the present study, was a round-shaped margin. This round contour not only favors adhesion and restoration placement, which reduces microleakage, ${ }^{24,25}$ but is also considered important for the longevity of adhesive restorations ${ }^{26}$ when associated with typical air abrasion cutting characteristics, namely, rough surfaces and a halo effect. ${ }^{19}$ This longevity is explained by a reduced incidence of fractures in comparison with cavity preparations that have defined acute angles. A round contour enables a gradual transition between tooth and restoration, and polymerization shrinkage stress is also diminished.

Restoration material bonding to the dental structure is an important factor in achieving a clinically successful treatment. According to Al-Omari et al. ${ }^{27}$ (2001), such a bonding depends on several variables, including cavity geometry and type of bonding agent. The authors also suggest that dental to-

\section{References}

1. Yip HK, Samaranayake LP. Caries removal techniques and instrumentation: a review. Clin Oral Invest. 1998;2(4):14854.

2. Eick JD, Johnson LN, Fromer JR, Neumann AW. Surface topography: its influence on wetting and adhesion in a dental adhesive system. J Dent Res. 1972;51(3):780-8.

3. Nakabayashi N, Kojima K, Masuhara E. The promotion of adhesion by the infiltration of monomers into tooth substrates. J Biomed Mater Res. 1982;16(3):265-73.

4. Banerjee A, Watson TF, Kidd EA. Dentine caries excavation: a review of current clinical techniques. Br Dent J. 2000;188(9):476-82.

5. Doerr RE. Principles associated with the use of highspeed rotary instruments. Dent Clin North Am. 1967;11(2):22-5.

6. Banerjee A, Kidd EA, Watson TF. Scanning electron microscopic observations of human dentine after mechanical caries excavation. J Dent. 2000;28(3):179-86. pography can influence the quality of the adhesive systems. Therefore, further studies of the behavior of the different adhesive systems (self-etch and total-etch) on dental surfaces treated with either high speed or air abrasion instruments are of crucial importance, specially because of the particular characteristics resulting from such cavity preparation techniques.

\section{Conclusion}

Based on the methodology of the present study, it was observed that the high speed technique was faster than the air abrasion technique for cavity preparation. No difference was found between the three dental substrates with regard to topography and presence of smear layer. The differences found in the present study were only in relation to the effects of the instruments used, since they determined the topography of the surface and type of smear layer.

\section{Acknowledgements}

The authors would like to thank the electronic microscopy and microanalysis laboratory (PEMM/ COPPE/ UFRJ) for performing the SEM, and professor Ronnir Raggio (NESC/ UFRJ) for the statistical analysis support.

7. Rome WJ, Doran JE, Walker WA $3^{\text {rd }}$. The efectiveness of Gly-Oxide and sodium hypochlorite in preventing smear layer formation. J Endod. 1985;2(7):281-8.

8. Tagami J, Tao L, Pashley DH, Horner JA. The permeability of dentine from bovine incisors in vitro. Arch Oral Biol. 1989;34(10):773-7.

9. Nakamichi I, Iwaku M, Fusayama T. Bovine teeth as possible substitutes in the adhesion test. J Dent Res. 1983;62(10):107681.

10. Abuabara A, Santos AJ, Aguiar FH, Lovadino JR. Evaluation of microleakage in human, bovine and swine enamels. Braz Oral Res. 2004;18(4):312-6.

11. Yazici AR, Ozgünaltay G, Dayangaç B. A scanning electron microscopic study of different caries removal techniques on human dentin. Oper Dent. 2002;27(4):360-6.

12. Pashley DH. Smear layer: physiological considerations. Oper Dent. 1984;3(Suppl):13-29. 
13. Siegel SS, Fraunhofer JAV. Assessing the cutting efficiency of dental diamond burs. J Am Dent Assoc. 1996;127(6):763-72.

14. Bester SP, de Wet FA, Nel JC, Driessen CH. The effect of airborne particle abrasion on the dentin smear layer and dentin: an in vitro investigation. Int J Prosthodont. 1995;8(1):46-50.

15. Fernandes MA, Fontana VF. Estudo comparativo in vitro da capacidade de desgaste de estrutura de esmalte dental em diferentes tempos, utilizando pontas de diamante e air-touch system. Rev CROMG. 2002;8(1):49-53.

16. Black RB. Air abrasive: some fundamentals. J Am Dent Assoc. 1950;41(6):701-10.

17. Vieira ASB, Alves MPS, Antunes LAA, Primo L, Maia LC. Abrasão ultrasônica versus alta rotação: avaliação do tempo de preparo cavitário e da microinfiltração. In: $21^{\mathrm{a}}$ Reunião Anual da SBPqO; 2004. Águas de Lindóia. Anais. São Paulo: Sociedade Brasileira de Pesquisa Odontológica; 2004. p. 172.

18. Vieira ASB, Alves MPS, Antunes LAA, Primo L, Maia LC. Topografia e presença de "smear layer" em dentes decíduos preparados com alta rotação e abrasão ultra-sônica in vitro. In: $22^{\mathrm{a}}$ Reunião Anual da SBPqO; 2005. Águas de Lindóia. Anais. São Paulo: Sociedade Brasileira de Pesquisa Odontológica; 2005. p. 175.

19. Laurell KA, Hess JA. Scanning electron micrographic effects of air-abrasion cavity preparation on human enamel and dentin. Quintessence Int. 1995;26(2):139-44.

20. Watson TF, Cook RJ. The influence of bur blade concentricity on high speed tooth cutting interaction: a video-rate confocal microscopic study. J Dent Res. 1995;74(11):1749-55.
21. Antunes LAA, Vieira ASB, Alves MPS, Maia LC. Influência de quatro tipos de pontas na topografia de preparos cavitários cinéticos em incisivos bovinos. In: $22^{\mathrm{a}}$ Reunião Anual da SBPqO; 2005. Águas de Lindóia. Anais. São Paulo: Sociedade Brasileira de Pesquisa Odontológica; 2005. p. 220.

22. Peruchi C, Santos-Pinto L, Santos-Pinto A, Barbosa e Silva E. Evaluation of cutting patterns produced in primary teeth by an air-abrasion system. Quintessence Int. 2002;33(4):279-83.

23. Santos-Pinto L, Peruchi C, Cordeiro R, Marker VA. Evaluation of cutting patterns produced with air-abrasion systems using different tip designs. Oper Dent. 2001;26(3):308-12.

24. Hamilton JC, Dennison JB, Stoffers KW, Welch KB. A clinical evaluation of air-abrasion treatment of questionable carious lesions. A 12-month report. J Am Dent Assoc. 2001;132(6):7629.

25. Hicks MJ, Parkins FM, Flaitz CM. Kinetic cavity preparation effects on secondary caries formation around resin restorations: a polarized light microscopic in vitro evaluation. ASDC J Dent Child. 2001;68(2):115-21.

26. Nordbo H, Leirskar J, Von Der Fehr FR. Saucer-shaped cavity preparations for posterior approximal resin composite restoration: observations up to 10 years. Quintessence Int. 1998;29(1):5-11.

27. Al-Omari WM, Mitchell CA, Cunningham JL. Surface roughness and wettability of enamel and dentine surfaces prepared with different dental burs. J Oral Rehabil. 2001;28(7):64550 . 